\title{
Comparison of the effects of dietary protein, androstenediol and forearm muscle area on radial bone variables in healthy prepubertal children
}

\author{
Lars Libuda $^{1 *}$, Stefan A. Wudy ${ }^{2}$, Eckhard Schoenau ${ }^{3}$ and Thomas Remer ${ }^{1}$ \\ ${ }^{1}$ Department of Nutrition and Health, Research Institute of Child Nutrition (FKE), Heinstueck 11, D-44225 Dortmund, \\ Germany \\ ${ }^{2}$ Steroid Research Unit, Centre of Child and Adolescent Medicine, Justus Liebig University of Giessen, 35392 Giessen, \\ Germany \\ ${ }^{3}$ Children's Hospital, University of Cologne, 50924 Cologne, Germany
}

(Received 12 April 2010 - Revised 4 August 2010 - Accepted 9 August 2010 - First published online 21 September 2010)

\begin{abstract}
Adequate dietary habits are supposed to be one of the most important modifiable factors in osteoporosis prevention. However, the importance of specific nutrients is controversial. We examined relevant nutrients which are supposed to have an impact on bone parameters and compared their effect sizes with those of two known predictors of bone development: bone-related muscle mass and androgen levels. We analysed nutritional, hormonal and anthropometric data from 107 prepubertal children participating in the Dortmund Nutritional and Anthropometric Longitudinally Designed Study. Diaphyseal bone mineral content (BMC), cortical area (CA), periosteal circumference, strength strain index and muscle area of the non-dominant forearm were measured by peripheral quantitative computed tomography. Data on long-term nutrient intakes (e.g. protein, Ca and vitamin D) were derived from $3 \mathrm{~d}$ weighed dietary records. Twenty-four hour urinary excretion rates of androgen metabolites including the sex steroid androstenediol were measured using GC-MS. Of all considered nutrients, only protein showed a trend for an association with BMC $(\beta=+0 \cdot 11 ; P=0 \cdot 073)$ and $\mathrm{CA}(\beta=+0 \cdot 11 ; P=0 \cdot 056)$ in stepwise linear regression models. None of the other considered dietary variables was associated with bone parameters. The size of the bone anabolic effect of protein was partly comparable with that of androstenediol. Even though boys gained more bone mass in comparison with girls, the protein effect did not differ between sexes. Bone-related muscle area and sex steroids have the strongest effects on prepubertal diaphyseal bone. However, dietary protein may have a similar bone anabolic influence compared with androstenediol. In children without explicit nutrient deficits, protein seems to be the most important dietary component for diaphyseal bone status.
\end{abstract}

Key words: Protein intake: Calcium intake: Dietary habits: Bone status: Prepubertal children

As the development of bone mass in childhood seems to be associated with the risk of osteoporosis and bone fractures in later adulthood, prevention of osteoporosis should ideally begin in childhood ${ }^{(1,2)}$. One modifiable factor that is discussed to play an important role in osteoporosis prevention is an adequate diet providing a sufficient nutrient intake (e.g. Ca, but also protein and vitamin $\mathrm{D})^{(3)}$. In this context, former recommendations ${ }^{(4)}$ for an optimal diet for bone development in childhood often focused on milk as a food group and especially $\mathrm{Ca}$ as a nutrient. However, a positive impact of higher intakes of $\mathrm{Ca}$ on bone health has not been unequivocally demonstrated. Accordingly, the sole supplementation of $\mathrm{Ca}$ does not seem to significantly reduce the risk of fracture in childhood or later life ${ }^{(5)}$.
Recent findings from cohort studies showed significant associations between bone mineral content (BMC) or bone mineral density and other nutrients, e.g. $\operatorname{protein}^{(6,7)}$, and dietary acid $\operatorname{load}^{(6,8)}$. The question arises whether these dietary components might perhaps be equally or even more important for bone status in childhood than Ca. However, previous corresponding studies primarily focused on the impact of single or only a few dietary components, but did not consider a wide range of potentially relevant dietary factors. Thus, it is currently not possible to compare the relevance of dietary factors for the bone status in childhood.

Furthermore, the importance of potential dietary effects in comparison with known predictors of bone development (e.g. anthropometrical variables and androgens)

Abbreviations: BMC, bone mineral content; CA, cortical area; DHEA, dehydroepiandrosterone; DONALD, Dortmund Nutritional and Anthropometric Longitudinally Designed; pQCT, peripheral quantitative computed tomography; PC, periosteal circumference; PRAL, potential renal acid load.

*Corresponding author: L. Libuda, fax +49 23171 15 81, email llibuda@gmx.de 
remains to be evaluated. It is well known that muscularity $^{(9)}$ and a favourable body composition ${ }^{(10)}$, i.e. the contribution of lean and fat mass, have a high beneficial impact on parameters of bone size. Additionally, results from a recent examination of the Dortmund Nutritional and Anthropometric Longitudinally Designed (DONALD) Study showed that the prepubertal level of the sex steroid 5 -androstene-3 $\beta, 17 \beta$-diol (androstenediol) predicts juvenile diaphyseal BMC and polar strength strain index in healthy children ${ }^{(11)}$.

Hence, the objective of the present study was to identify the strongest long-term dietary predictors of prepubertal diaphyseal bone status of healthy children participating in the DONALD study and to investigate how important these dietary effects were in relation to the impact of muscularity-related anthropometrical variables (e.g. muscle area) and androstenediol levels. The objective of the present study was to compare for the first time the effects of dietary components with those of anthropometrical variables and sex steroids on radial bone status of healthy prepubertal children.

\section{Material and methods}

\section{Study sample and design}

The study sample consisted of a subcohort of participants from the DONALD study. The DONALD study is an ongoing open cohort study that started in 1985 in Dortmund, Germany, and investigates the relationship between nutrition, development and metabolism in subjects between infancy and early adulthood. Until now, more than 1200 subjects have participated in the DONALD study. About forty subjects are enrolled in the DONALD study each year. The regular, non-invasive assessments that take place in intervals of 1 year include $3 \mathrm{~d}$ weighed dietary records, anthropometry, urine sampling, as well as interviews on lifestyle and medical assessments. Tanner stages are assessed by a study paediatrician. Details of the study protocol have previously been described ${ }^{(12)}$.

For the present examination, we considered those subjects who participated in a subproject of the DONALD study between July 1998 and June 1999 that included a single peripheral quantitative computed tomography (pQCT) measurement of the non-dominant forearm ${ }^{(13,14)}$. Overall, the pQCT was carried out in 371 participants. Of these, 191 participants had at least three of five possible plausible $3 \mathrm{~d}$ dietary records in the 4 years before bone analysis and a $24 \mathrm{~h}$ urine sample at the time of the pQCT. Implausible dietary records were excluded using ageand sex-specific cut-off values for the ratio of reported total energy intake and predicted $\mathrm{BMR}^{(15)}$ that was calculated by equations using measured height and weight ${ }^{(16)}$. Finally, 107 prepubertal (Tanner stage 1) children were included in the examination.

\section{Ethical approval}

The DONALD study was approved by the ethical committee of the Rheinische Friedrich-Wilhelms-Universität Bonn and with respect to bone analysis by the Federal Office for Radiation Protection (Salzgitter, Germany). All examinations and assessments are performed with parental, and later on with the children's written consent.

\section{Dietary survey}

In general, 3d weighed dietary records are used for the assessment of food consumption in the DONALD study. Details of the dietary survey are provided elsewhere ${ }^{(12)}$. In short, the parents of the children or the older subjects themselves weigh and record all foods and beverages before consumption as well as leftovers on 3 consecutive days. The first day of dietary recording can be chosen by the participant within a given period of time. Individual energy and nutrient intakes are calculated as arithmetic means of the three recorded days using our in-house nutrient database LEBTAB $^{(17)}$, which contains detailed data on the energy and nutrients content of all recorded food items and is continuously updated.

For the present examination, we calculated the long-term consumption as the mean value of each dietary record in the 4 years before pQCT for dietary factors that are discussed to have a potential impact on bone parameters: $\mathrm{Ca}$, protein, vitamin D and dietary potential renal acid load (PRAL) (all are given as densities, i.e. in relation to total energy intake). Dietary PRAL was calculated according to Remer et $a l .{ }^{(18)}$ using the following equation:

$$
\begin{aligned}
\operatorname{PRAL}(\mathrm{mEq} / \mathrm{d})= & 0.4888 \times \operatorname{protein}(\mathrm{g} / \mathrm{d})+0.0366 \\
& \times \operatorname{phosphorus}(\mathrm{mg} / \mathrm{d})-0.0205 \\
& \times \operatorname{potassium}(\mathrm{mg} / \mathrm{d})-0.0263 \\
& \times \text { magnesium }(\mathrm{mg} / \mathrm{d}) .
\end{aligned}
$$

The approach of PRAL calculation omits $\mathrm{Ca}$ intake and therefore allows to separately assess the association of $\mathrm{Ca}$ with bone status. Furthermore, the model considers the different absorption rates of minerals and mean values of S-containing amino acids in proteins. The PRAL model has already been validated not only in adults ${ }^{(19)}$ but also in children and adolescents ${ }^{(18)}$.

\section{Anthropometric measurements}

According to the study protocol, anthropometric measurements are performed from the age of 2 years onwards at each annual visit by trained nurses, with the children dressed in underwear only and barefoot. Standing height is measured to the nearest $0 \cdot 1 \mathrm{~cm}$ using a digital telescopic stadiometer (Harpenden; Holtain Ltd, Crymych, UK). Weight is measured to the nearest $0 \cdot 1 \mathrm{~kg}$ using an 
electronic scale (Seca 753E; Seca Gmbh \& Co. KG, Hamburg, Germany). Triceps and subscapular skinfolds are measured on the right side of the body to the nearest $0 \cdot 1 \mathrm{~mm}$ using a Holtain caliper (Holtain Limited, Crymych, UK). The sum of both skinfolds was used for the estimation of body fat percentage according to the equations of Slaughter et al. ${ }^{(20)}$. Sex- and age-independent BMI standard deviation scores were calculated using the German national reference data ${ }^{(21)}$

\section{Steroid hormone analysis}

GC-MS analyses were performed to detect individual $24 \mathrm{~h}$ urinary excretion rates of steroid hormones. Besides 5-androstene-3 $\beta, 17 \beta$-diol (androstenediol), we quantified further androgen metabolites such as dehydroepiandrosterone (DHEA), 16 $\alpha$-hydroxy-DHEA and 5-androstene-3 $\beta, 16-$ $\alpha, 17 \beta$-triol ${ }^{(22)}$. The sum of DHEA and its 16-hydroxylated downstream metabolites represents the main direct metabolites of DHEA and DHEA sulphate ${ }^{(22)}$. Androstenediol was considered as a potential exposure variable in linear regression models, because prepubertal levels of this sex steroid $^{(23,24)}$ have already been identified as a strong predictor of bone status in late puberty in a previous examination of the DONALD study ${ }^{(11)}$.

\section{Peripheral quantitative computed tomography}

A XCT-2000 device (Stratec, Inc., Pforzheim, Germany) equipped with a low-energy X-ray tube $(38 \mathrm{keV})$ was used for the pQCT measurement of bone and muscle variables of the non-dominant forearm at the maximum circumference, i.e. at a distance to the ulnar styloid process of $65 \%$ of the forearm length proximal to the radial endplate ${ }^{(13)}$. A 2 mm-thick single tomographic slice was sampled at a voxel size of $0.4 \times 0.4 \times 2 \mathrm{~mm}$. Image processing and the calculation of numerical values were performed using the manufacturer's software package (software version 5.40).

Cortical area (CA), i.e. the cross-sectional area of cortical bone, was determined by detecting the outer and inner cortical bone contour at a threshold of $710 \mathrm{mg} / \mathrm{cm}^{3}$. The same threshold was also used for the identification of BMC, which is defined as the mass of mineral (in $\mathrm{mg}$ ) per unit of axial bone length (in $\mathrm{mm}$ ). For the determination of the periosteal circumference (PC), a cylindrical bone shape was assumed, whereby the outer bone radius was calculated as follows:

$$
\text { Outer bone radius }=(\text { total area } / \pi)^{0.5} \text {. }
$$

Strength strain index as an indicator of bone stability was calculated as the product of section modulus and cortical density normalised to the maximal physiological cortical density of human bones ${ }^{(14)}$. Besides these bone variables, we also measured the cross-sectional muscle area at $65 \%$ of the ulnar length using a built-in software algorithm to separate muscle from bone and fat tissue.

\section{Statistical analysis}

All the statistical tests were performed using SAS ${ }^{\circledR}$ procedures (version 91.3, 2002-3; Statistical Analysis Systems, Cary, NC, USA). In all statistical tests, a $P$ value $<0.05$ was considered as significant.

Descriptive data are given as median and interquartile range. Sex differences in anthropometrics, hormones and dietary variables were tested using the Wilcoxon rank sum test. Stepwise linear regression analyses in three stages were applied to identify predictors of prepubertal bone variables (CA, BMC, PC and strength strain index). All variables, i.e. outcome and predictor variables, were checked for normality and $\log$ transformed when required before entering the regression models. In model 1 , the anthropometrical variables at the time of the pQCT, i.e. local muscle area, age, sex and BMI standard deviation scores and body fat percentage as indicators of body composition, were considered as potential predictors. Only those variables with $P$ values $<0 \cdot 1$ for the association with the respective bone variable were kept in model 2 , which also accounted for $24 \mathrm{~h}$ urinary excretion of androstenediol at the time of the pQCT. Apart from relevant variables that were identified in steps 1 and 2, the final model tested for the effects of long-term dietary variables, i.e. dietary protein intake, Ca, vitamin D and PRAL. Standardised $\beta$-values were computed for the comparison of the effect sizes of the predictor variables on bone status. A post hoc two-tailed power analysis with $\alpha=0.05$ was performed that yielded a power of 0.80002 for protein density.

Additionally, least-square means and 95\% CI of BMC and CA were computed for categories of muscle area, androstenediol excretion, dietary protein and $\mathrm{Ca}$ in order to graphically illustrate the impact of these potential predictor variables. Therefore, muscle area, androstenediol excretion, dietary protein density ( $g$ protein intake/MJ energy intake) and dietary Ca density (mg Ca intake/MJ energy intake) were subdivided into three categories, respectively (low, $<25$ th percentile; middle, $\geq 25$ th percentile and $<75$ th percentile; high, $\geq 75$ th percentile). Each of the least-square means was adjusted for the respective three other (continuous) predictor variables, i.e. muscle area, dietary protein and $\mathrm{Ca}$ in the case of the androstenediol categories.

As regression analyses mostly did not indicate any interaction between sex and the association of anthropometrical variables with bone variables in the basic models, data from girls and boys were pooled for analyses.

\section{Results}

Median and interquartile ranges of anthropometrical variables, steroid hormones and long-term dietary data 
Table 1. Anthropometrical variables, steroid hormones, bone characteristics and dietary characteristics in a sample of 107 healthy prepubertal children at the time of the peripheral quantitative computed tomography (pQCT) measurement

(Medians and quartiles)

\begin{tabular}{|c|c|c|c|c|c|c|c|}
\hline & \multicolumn{3}{|c|}{ Boys ( $n 57)$} & \multicolumn{3}{|c|}{ Girls $(n 50)$} & \multirow[b]{2}{*}{$P^{*}$} \\
\hline & Median & Q1 & Q3 & Median & Q1 & Q3 & \\
\hline \multicolumn{8}{|l|}{ Anthropometrics } \\
\hline Age (years) & $8 \cdot 2$ & $7 \cdot 0$ & 10.5 & 8.0 & $7 \cdot 0$ & $9 \cdot 5$ & 0.24 \\
\hline $\mathrm{BMI}\left(\mathrm{kg} / \mathrm{m}^{2}\right)$ & $16 \cdot 3$ & $15 \cdot 1$ & $17 \cdot 2$ & $15 \cdot 7$ & $15 \cdot 1$ & $17 \cdot 6$ & 0.48 \\
\hline BMI-SDS & 0.0 & -0.7 & 0.5 & -0.2 & -0.6 & 0.7 & 0.78 \\
\hline Body fat (\%) & $13 \cdot 8$ & 11.7 & $18 \cdot 0$ & $17 \cdot 1$ & $14 \cdot 3$ & 21.4 & 0.001 \\
\hline \multicolumn{8}{|l|}{ Hormone variables } \\
\hline Androstenediol $(\mu \mathrm{g} / \mathrm{d})$ & $11 \cdot 1$ & 5.9 & $24 \cdot 1$ & $7 \cdot 2$ & $3 \cdot 8$ & $10 \cdot 9$ & 0.01 \\
\hline DHEA $(\mu \mathrm{g} / \mathrm{d})$ & 137.5 & 84.9 & $225 \cdot 6$ & $86 \cdot 7$ & $66 \cdot 9$ & $150 \cdot 7$ & $<0.01$ \\
\hline \multicolumn{8}{|l|}{ Bone variables } \\
\hline Bone mineral content $(\mathrm{mg} / \mathrm{mm})$ & $45 \cdot 6$ & $39 \cdot 6$ & $52 \cdot 7$ & $40 \cdot 6$ & $29 \cdot 1$ & $52 \cdot 0$ & 0.04 \\
\hline Cortical area $\left(\mathrm{mm}^{2}\right)$ & $44 \cdot 8$ & $39 \cdot 0$ & $51 \cdot 0$ & $40 \cdot 9$ & $30 \cdot 2$ & $50 \cdot 5$ & 0.03 \\
\hline Periosteal circumference (mm) & $32 \cdot 7$ & 29.9 & $35 \cdot 0$ & 31.7 & $30 \cdot 0$ & $33 \cdot 6$ & 0.17 \\
\hline Polar bone strength strain index $\left(\mathrm{mm}^{3}\right)$ & $139 \cdot 0$ & $109 \cdot 1$ & $172 \cdot 9$ & $118 \cdot 8$ & $94 \cdot 1$ & $153 \cdot 6$ & 0.01 \\
\hline Muscle area $\left(\mathrm{mm}^{2}\right)$ & 1961.9 & $1704 \cdot 4$ & $2180 \cdot 5$ & $1737 \cdot 7$ & $1542 \cdot 3$ & $2025 \cdot 1$ & 0.01 \\
\hline \multicolumn{8}{|l|}{ Dietary variables† } \\
\hline Total energy $(\mathrm{MJ} / \mathrm{d})$ & $6 \cdot 3$ & $5 \cdot 6$ & $6 \cdot 9$ & $5 \cdot 7$ & $5 \cdot 1$ & $6 \cdot 2$ & $<0.001$ \\
\hline \multicolumn{8}{|l|}{ Protein } \\
\hline$g / d$ & $46 \cdot 1$ & $40 \cdot 9$ & 54.5 & $42 \cdot 7$ & 37.9 & $48 \cdot 2$ & 0.01 \\
\hline $\mathrm{g} / \mathrm{MJ}$ & 7.5 & 6.9 & 8.3 & 7.6 & 7.0 & 8.3 & 0.65 \\
\hline $\mathrm{g} / \mathrm{kg}$ & $2 \cdot 0$ & 1.8 & $2 \cdot 2$ & $2 \cdot 0$ & $1 \cdot 7$ & $2 \cdot 1$ & 0.18 \\
\hline \multicolumn{8}{|l|}{$\mathrm{Ca}$} \\
\hline $\mathrm{mg} / \mathrm{d}$ & $712 \cdot 3$ & $636 \cdot 6$ & 837.2 & 654.9 & $560 \cdot 2$ & 778.8 & $<0.05$ \\
\hline $\mathrm{mg} / \mathrm{MJ}$ & 119.9 & 98.6 & $133 \cdot 7$ & $120 \cdot 6$ & $101 \cdot 2$ & $135 \cdot 0$ & 0.49 \\
\hline \multicolumn{8}{|l|}{ Vitamin D } \\
\hline$\mu \mathrm{g} / \mathrm{d}$ & 1.8 & 1.4 & 2.5 & 1.6 & 1.3 & 1.9 & 0.05 \\
\hline$\mu \mathrm{g} / \mathrm{MJ}$ & 0.28 & 0.23 & 0.36 & 0.28 & 0.23 & 0.34 & 0.88 \\
\hline \multicolumn{8}{|l|}{ PRAL } \\
\hline $\mathrm{mEg} / \mathrm{d}$ & $8 \cdot 8$ & 5.4 & 11.6 & $8 \cdot 3$ & $5 \cdot 3$ & $12 \cdot 7$ & 0.74 \\
\hline $\mathrm{mEq} / \mathrm{MJ}$ & 1.4 & 0.9 & 1.8 & 1.5 & 0.7 & $2 \cdot 0$ & 0.53 \\
\hline
\end{tabular}

Q, quartile; BMI-SDS, BMI standard deviation scores; DHEA, dehydroepiandrosterone; PRAL, potential renal acid load.

* Sex differences were tested using the Wilcoxon rank sum test.

† Long-term dietary characteristics in the 4 years before the PQCT measurement.

including all the dependent and independent variables are given in Table 1. Despite a comparable BMI, the prepubertal body composition differed by sex as body fat was significantly lower in boys in comparison with girls. Additionally, we observed a higher excretion of androstenediol, DHEA and its 16-hydroxylated downstream metabolites in boys, and also higher values of muscle area and all bone variables except for PC.

Long-term intakes of total energy and most absolute values of dietary variables were greater in boys compared with girls. However, relative values related to total energy intake showed no sex differences in dietary densities. In both sexes, long-term Ca intake was slightly below the recommended $800 \mathrm{mg} / \mathrm{d}$ for children aged $4-8$ years proposed by the National Institute of Medicine ${ }^{(25)}$. Vitamin D intake did not reach the recommended $5 \mu \mathrm{g} / \mathrm{d}$, but was not much below the proposed adequate intake level of $1.9-2.5 \mu \mathrm{g}$ that should be sufficient when sun exposure or skin pigmentation limits vitamin D skin synthesis ${ }^{(25)}$. In contrast, both absolute intake and intake per kg body weight of protein were twice as high as the reference values $^{(26)}$. Median PRAL values indicated a modest dietary acid load.
Results from the first step of the linear regression models showed that $\log$ values of the forearm muscle area were strongly associated with all bone variables (Table 2). Additionally, age predicted all bone outcomes except for PC in model 1. BMI standard deviation score was significantly associated with BMC and CA in model 1. Sex and $\log$ values of body fat percentage were not associated with any bone variable. The associations for BMI standard deviation scores and age disappeared after consideration of androstenediol and dietary variables in the following models. Androstenediol levels were significantly positively associated with all bone parameters except for PC. These associations remained significant after consideration of dietary variables in model 3 . Of all dietary variables, only protein showed a positive trend with BMC and also with CA. None of the other dietary variables entered the models.

With regard to all considered variables, forearm muscle area was the strongest predictor of all bone variables, with standardised $\beta$-values ranging from 0.64 to 0.71 in the fully adjusted models. Androstenediol secretion was found to be the second most important predictor with standardised $\beta$-values between $0 \cdot 18$ and $0 \cdot 27$. The standardised $\beta$-value of protein was $0 \cdot 11$. 


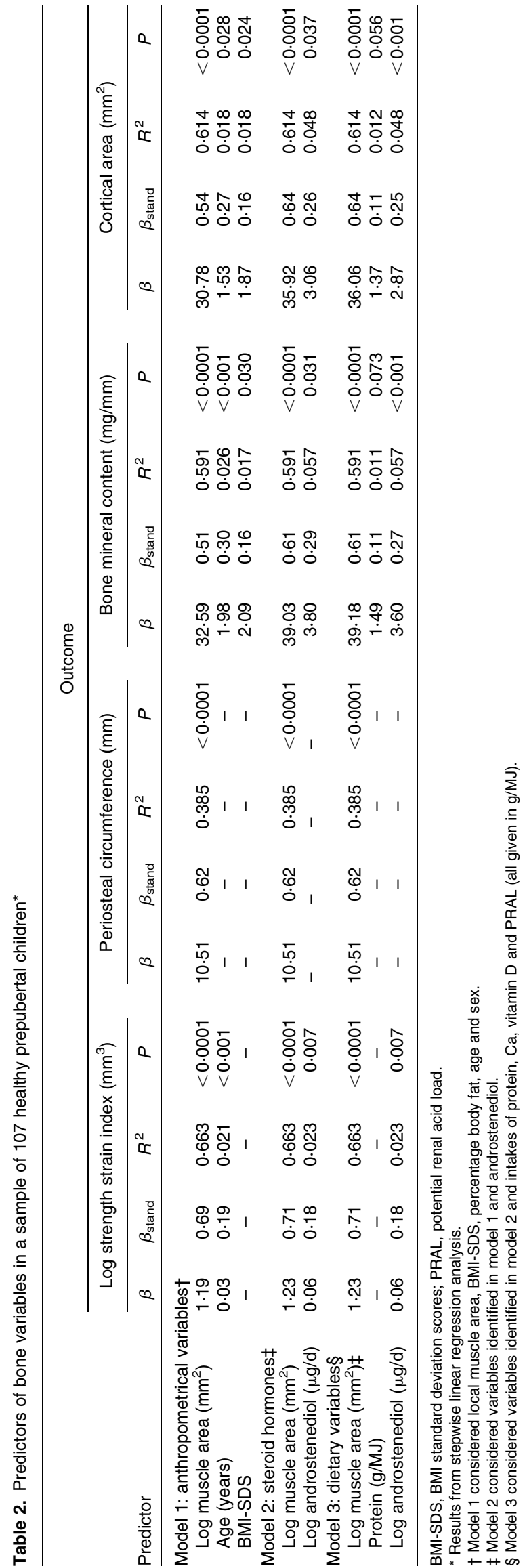

The importance of protein was shown in Fig. 1, which illustrates the means of BMC and CA according to the categories of muscle area, androstenediol excretion, protein density and Ca density. Both BMC and CA increased especially between the lowest and the middle categories of protein intake. The slope of BMC and CA between these two groups was comparable to the increase between the lowest and the middle categories of androstenediol excretion. However, the $P$ value for bone parameter differences by categories of protein density showed only a trend and was not statistically significant.

\section{Discussion}

The main finding of the present examination was the positive trend between long-term protein intake and both BMC and CA in healthy prepubertal boys and girls, which was independent from the bone anabolic effect of muscularity and androgens. Bone-related muscle area was found to be the most important predictor of diaphyseal bone variables followed by the sex steroid androstenediol. The impact of a protein increase from the lowest to middle intake category was comparable with that of the sex steroid androstenediol varying between its lowest and medium excretion categories. None of the other considered dietary variables showed a trend with any of the bone variables.

The observed positive trends for protein intake support the increasing evidence of a bone anabolic effect of dietary protein $^{(6,7,27,28)}$. Recently, a positive effect of dietary protein was already demonstrated for adults in a meta-analysis of randomised controlled trials ${ }^{(29)}$. In the past, an increase in protein intake was supposed to have a detrimental influence on bone parameters ${ }^{(30)}$ due to the acidifying impact of S-containing amino acids that leads to higher urinary Ca losses. Today, it is well known that an increase in protein intake also stimulates insulin-like-growth factor 1 secretion and thus may cause bone anabolism in total despite its existing acidifying effect ${ }^{(30,31)}$.

A higher protein intake at a constant PRAL level has been recently shown to be significantly associated with stronger bone parameters in an examination of the DONALD study including children and adolescents ${ }^{(6)}$. The lack of significance for dietary protein in the present examination might be due to the overall relatively high protein intake in our prepubertal study population. The present results (Fig. 1) suggest that there may be no further bone anabolic effect of protein in the highest intake category and therefore no linear cause-and-effect relationship. The stimulating effect of protein on insulin-like-growth factor 1 secretion may become weaker at high protein intake levels and could be even levelled by the acidifying impact of S-containing amino acids. This assumption is supported by Ilich \& Kerstetter $^{(3)}$ who supposed that diets which are particularly high in protein could even have a detrimental effect on bone. In their opinion, a protein intake of $1.0-1.5 \mathrm{~g} / \mathrm{kg}$ body weight may be optimal for 
(a)

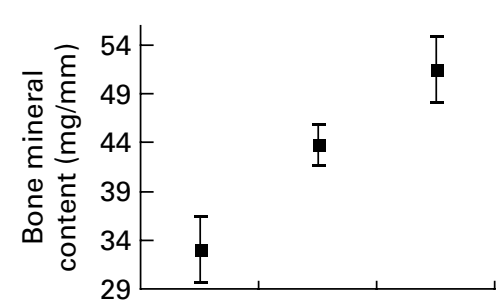

(e)

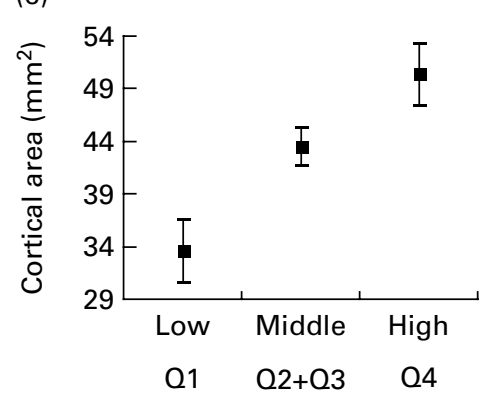

(1187-1640) (1643-2101) (2114-2955) (b)

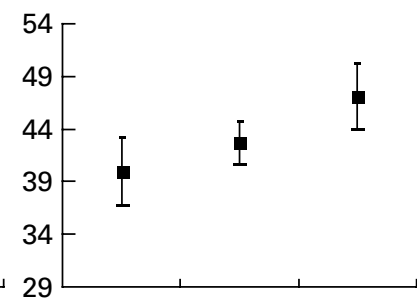

(f)

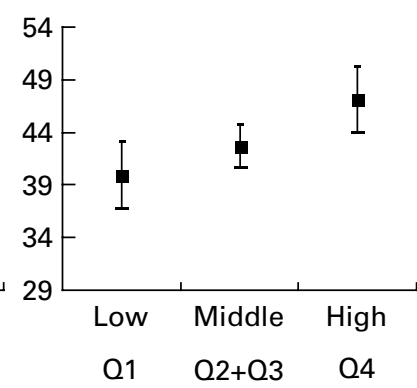

$(1 \cdot 6-5 \cdot 1)(5 \cdot 1-18 \cdot 1)(18 \cdot 1-80 \cdot 0)$ (c)

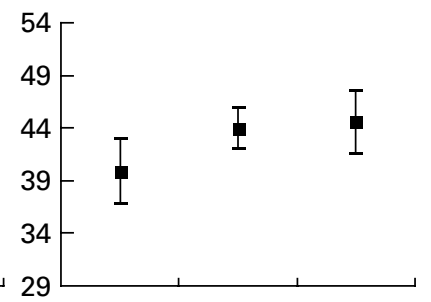

(g)

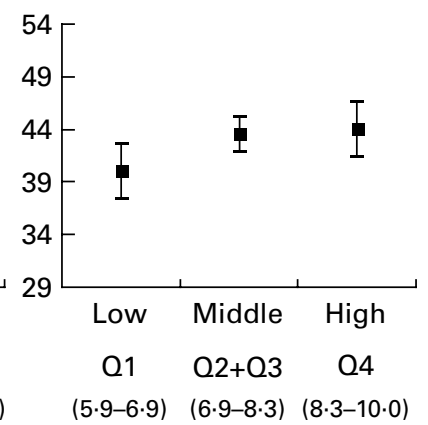

(d)

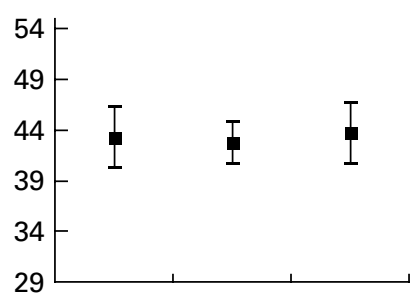

(h)

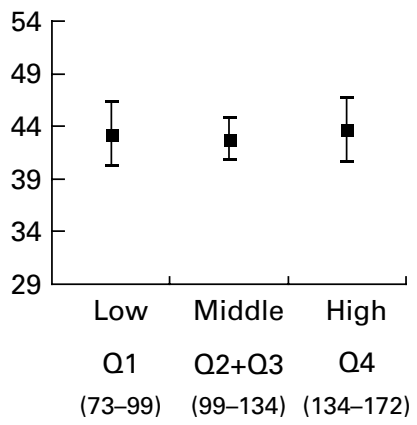

Fig. 1. Bone mineral content and cortical area by categories of muscle area $\left(\mathrm{mm}^{2}\right)\left((\mathrm{a}) P_{\text {diff }}<0.001\right.$, (e) $\left.P_{\text {diff }}<0.001\right)$, urinary $24 \mathrm{~h}$ androstenediol excretion $(\mu \mathrm{g} / \mathrm{d})\left((\mathrm{b}) P_{\text {diff }}=0.013\right.$, (f) $\left.P_{\text {diff }}=0.029\right)$, protein density (g protein intake/MJ energy intake) $\left((\mathrm{c}) P_{\text {diff }}=0.074,(\mathrm{~g}) P_{\text {diff }}=0.073\right)$ and Ca density (mg Ca intake/MJ energy intake) ((d) $P_{\text {diff }}=0.874$, (h) $\left.P_{\text {diff }}=0.963\right)$. All the variables were subdivided into three categories, respectively (low, $<25$ th percentile; middle, $\geq 25$ th percentile and $<75$ th percentile; high, $\geq 75$ th percentile). Data are least-square means $(95 \% \mathrm{Cl}$ ) adjusted for the respective three other (continuous) predictor variables, i.e. muscle area, dietary protein and $\mathrm{Ca}$ in the case of androstenediol categories. Q, quartile.

bone health ${ }^{(3)}$. The present results indicate that even protein intakes of $2.0 \mathrm{~g} / \mathrm{kg}$ (median in our sample) could be beneficial for bone health at least in prepubertal children. This beneficial effect of high protein intakes is in line with findings from Chevalley et al. ${ }^{(32)}$ who observed that an increase in physical activity at a protein intake of $2.0 \mathrm{~g} / \mathrm{kg}$ was associated with a higher BMC in prepubertal boys in comparison to a similar increase in physical activity at a protein intake of $1.5 \mathrm{~g} / \mathrm{kg}$ body weight. However, the optimal protein intake for bone strength probably depends on protein sources ${ }^{(33)}$, Ca intake ${ }^{(27)}$, consumption of alkalirich foods (fruits and vegetables) ${ }^{(6,27)}$ and physical $\operatorname{activity}^{(32)}$.

The American Academy of Pediatrics recommends adequate intakes of $\mathrm{Ca}$ in childhood and adolescence for the promotion of bone health and the prevention of osteoporosis $^{(34)}$. In this context, Ilich \& Kerstetter $^{(3)}$ suggested that bone variables would only respond to increases in $\mathrm{Ca}$ intakes if the baseline supply was deficient, i.e. additional $\mathrm{Ca}$ intake would have no further relevant effect on bone if the intake levels were already sufficient. The general good supply with nutrients in our sample could therefore be one reason for the missing association between $\mathrm{Ca}$ intake and bone parameters in the present examination, although mean long-term $\mathrm{Ca}$ intake was slightly lower than the recommended values. Heaney ${ }^{(35)}$ postulated that vitamin $\mathrm{D}$ status has to be considered together with $\mathrm{Ca}$ intake. As the DONALD study is not invasive, we were unable to include serum 25-hydroxy-vitamin D concentrations in our data analysis, but we did include dietary intakes of vitamin D. Skin vitamin D biosynthesis was not factored into the estimated intake of vitamin D. Therefore, data from the DONALD study might not be fully appropriate to evaluate the specific contribution of $\mathrm{Ca}$ and vitamin $\mathrm{D}$ for prepubertal bone status. However, based on the results of the present study, we hypothesise that differences in protein intake may have a stronger effect on diaphyseal bone parameters than increases in $\mathrm{Ca}$ intake in prepubertal children with a good nutrient supply.

In a previous data analysis of the DONALD study, a significant negative association for PRAL with several bone parameters was observed in a sample of 229 prepubertal and pubertal children ${ }^{(6)}$. The inverse relationship between dietary acid load and bone parameters, which was confirmed in further studies ${ }^{(36,37)}$, could rely on a higher bone resorption due to osteoclast stimulation ${ }^{(8,36)}$. In contrast, we did not observe a significant association between PRAL and bone parameters in the present examination. The discrepancy with the above-mentioned analysis of the DONALD study could be due to the smaller sample size in our examination. Another reason for the missing association could be the small variation in dietary PRAL in the present study sample of prepubertal children. However, we cannot exclude that a higher sample size might have resulted in clearer associations for dietary PRAL and perhaps also for other nutrients with bone parameters.

For all examined bone parameters, muscle area of the forearm was the most important predictor variable. The strong relationship between bone and muscle area is the basis of the mechanostat theory, which posits that bone mass and architecture changes result from 
muscle-dependent stimuli ${ }^{(38)}$. Accordingly, encouragement of physical activity to increase muscle mass from childhood onwards could be the most powerful tool for osteoporosis prevention.

The main limitation of the present study was the fact that only one PQCT measurement was carried out in each subject. Thus, we were not able to estimate effects of changes in dietary habits on the concurrent bone development. Accordingly, our data are not suitable to prove a causality link, but they are capable of identifying associations. Another limitation of our examination was the missing information on physical activity. However, we were able to indirectly adjust for physical activity using pQCT information on muscle area at the analysed bone site. We also had no reliable information on long-term sunlight exposure for the present study sample. Therefore, we are only able to discuss the role of dietary vitamin $\mathrm{D}$, but not the importance of vitamin D in total.

An advantage of our approach could be the application of pQCT instead of the dual-energy X-ray absorptiometry method that is often used in other cohort studies. The pQCT method is known to provide a sensitive and more specific measurement of bone quality in children ${ }^{(39-41)}$. Weighed dietary records, which were used in the DONALD study, are regarded as the 'gold standard' for dietary surveys ${ }^{(42)}$. Another advantage is the consideration of long-term dietary data over 4 years of study participation, which produces a more accurate estimation of dietary behaviour than a single survey.

The present examination compared for the first time the effects of dietary components with those of anthropometrical variables and sex steroids on bone status of healthy prepubertal children. The present results suggest that muscle area has the strongest effect followed by the sex steroid androstenediol and protein intake, which was found to be the strongest dietary predictor of diaphyseal bone in prepubertal boys and girls with a good general nutrient supply. The bone anabolic impact of protein, increasing from the lowest to middle intake category, was found to be comparable with that of the sex steroid androstenediol, varying between its lowest and medium excretion categories in prepuberty. An adequate protein intake appears to be one of the most important components of osteoporosis prevention.

\section{Acknowledgements}

We are very grateful to the staff of the Research Institute of Child Nutrition for carrying out the anthropometric measurements and for collecting and coding the dietary records. The DONALD study is funded by the Ministry of Science and Research of North Rhine Westphalia, Germany. The contributions of the authors were as follows: L. L. and T. R. designed the research and performed the initial statistical analyses; L. L. conducted further analyses and wrote the manuscript; S. A. W. and E. S. provided critical input on the data analyses and on the early versions of the manuscript; T. R. supervised the study. None of the authors had any personal or financial conflicts of interest.

\section{References}

1. Faulkner RA \& Bailey DA (2007) Osteoporosis: a pediatric concern? Med Sport Sci 51, 1-12.

2. Bachrach LK (2007) Consensus and controversy regarding osteoporosis in the pediatric population. Endocr Pract 13, $513-520$.

3. Ilich JZ \& Kerstetter JE (2000) Nutrition in bone health revisited: a story beyond calcium. J Am Coll Nutr 19, 715-737.

4. Murray TM (1996) Prevention and management of osteoporosis: consensus statements from the Scientific Advisory Board of the Osteoporosis Society of Canada. 4. Calcium nutrition and osteoporosis. CMAJ 155, 935-939.

5. Winzenberg T, Shaw K, Fryer J, et al. (2006) Effects of calcium supplementation on bone density in healthy children: meta-analysis of randomised controlled trials. BMJ 333, 775.

6. Alexy U, Remer T, Manz F, et al. (2005) Long-term protein intake and dietary potential renal acid load are associated with bone modeling and remodeling at the proximal radius in healthy children. Am J Clin Nutr 82, 1107-1114.

7. Vatanparast H, Bailey DA, Baxter-Jones AD, et al. (2007) The effects of dietary protein on bone mineral mass in young adults may be modulated by adolescent calcium intake. J Nutr 137, 2674-2679.

8. New SA, MacDonald HM, Campbell MK, et al. (2004) Lower estimates of net endogenous non-carbonic acid production are positively associated with indexes of bone health in premenopausal and perimenopausal women. Am J Clin Nutr 79, $131-138$.

9. Schonau E, Schwahn B \& Rauch F (2002) The muscle-bone relationship: methods and management - perspectives in glycogen storage disease. Eur J Pediatr 161, Suppl. 1, $\mathrm{S} 50-\mathrm{S} 52$.

10. Taes YE, Lapauw B, Vanbillemont G, et al. (2009) Fat mass is negatively associated with cortical bone size in young healthy male siblings. J Clin Endocrinol Metab 94, 2325-2331.

11. Remer T, Manz F, Hartmann MF, et al. (2009) Prepubertal healthy children's urinary androstenediol predicts diaphyseal bone strength in late puberty. J Clin Endocrinol Metab $\mathbf{9 4}$, 575-578.

12. Kroke A, Manz F, Kersting M, et al. (2004) The DONALD study. History, current status and future perspectives. Eur $J$ Nutr 43, 45-54.

13. Neu CM, Rauch F, Rittweger J, et al. (2002) Influence of puberty on muscle development at the forearm. Am J Physiol Endocrinol Metab 283, E103-E107.

14. Schoenau E, Neu CM, Rauch F, et al. (2001) The development of bone strength at the proximal radius during childhood and adolescence. J Clin Endocrinol Metab 86, 613-618.

15. Sichert-Hellert W, Kersting M \& Schoch G (1998) Underreporting of energy intake in 1 to 18 year old German children and adolescents. Z Ernahrungswiss 37, 242-251.

16. Schofield WN (1985) Predicting basal metabolic rate, new standards and review of previous work. Hum Nutr Clin Nutr 39, Suppl. 1, 5-41.

17. Sichert-Hellert WKM, Chahda C, Schaefer R, et al. (2007) German food composition database for dietary evaluations in children and adolescents. J Food Compost Anal 20, 63-70. 
18. Remer T, Dimitriou T \& Manz F (2003) Dietary potential renal acid load and renal net acid excretion in healthy, free-living children and adolescents. Am J Clin Nutr 77, $1255-1260$.

19. Remer T \& Manz F (1994) Estimation of the renal net acid excretion by adults consuming diets containing variable amounts of protein. Am J Clin Nutr 59, 1356-1361.

20. Slaughter MH, Lohman TG, Boileau RA, et al. (1988) Skinfold equations for estimation of body fatness in children and youth. Hum Biol 60, 709-723.

21. Kromeyer-Hauschild K, Wabitsch M, Kunze D, et al. (2001) Percentiles of body mass index in children and adolescents evaluated from different regional German studies (in German). Monatsschrift Kinderheilkd 149, 807-818.

22. Remer T, Boye KR, Hartmann MF, et al. (2005) Urinary markers of adrenarche: reference values in healthy subjects, aged 3-18 years. J Clin Endocrinol Metab 90, 2015-2021.

23. Mo Q, Lu SF \& Simon NG (2006) Dehydroepiandrosterone and its metabolites: differential effects on androgen receptor trafficking and transcriptional activity. J Steroid Biochem Mol Biol 99, 50-58.

24. Lardy H, Marwah A \& Marwah P (2005) C(19)-5-ene steroids in nature. Vitam Horm 71, 263-299.

25. Institute of Medicine \& Food and Nutrition Board ed. (1997) Dietary Reference Intakes of Calcium, Phosphorus, Magnesium, Vitamin D, and Fluoride. Washington, DC: National Academic Press.

26. Deutsche Gesellschaft für Ernährung (2001) Referenzwerte für die Nährstoffzufubr (Reference Values for Nutrient Intake). Frankfurt am Main: Umschau Braus.

27. Ginty F (2003) Dietary protein and bone health. Proc Nutr Soc 62, 867-876.

28. Conigrave AD, Brown EM \& Rizzoli R (2008) Dietary protein and bone health: roles of amino acid-sensing receptors in the control of calcium metabolism and bone homeostasis. Annu Rev Nutr 28, 131-155.

29. Darling AL, Millward DJ, Torgerson DJ, et al. (2009) Dietary protein and bone health: a systematic review and meta-analysis. Am J Clin Nutr 90, 1674-1692.
30. Rizzoli R \& Bonjour JP (2004) Dietary protein and bone health. J Bone Miner Res 19, 527-531.

31. Bonjour JP, Ammann P, Chevalley T, et al. (2001) Protein intake and bone growth. Can J Appl Physiol 26, Suppl., S153-S166.

32. Chevalley T, Bonjour JP, Ferrari S, et al. (2008) High-protein intake enhances the positive impact of physical activity on BMC in prepubertal boys. J Bone Miner Res 23, 131-142.

33. Heaney RP \& Layman DK (2008) Amount and type of protein influences bone health. Am J Clin Nutr 87, 1567S-1570S.

34. Greer FR \& Krebs NF (2006) Optimizing bone health and calcium intakes of infants, children, and adolescents. Pediatrics 117, 578-585.

35. Heaney RP (2007) Bone health. Am J Clin Nutr 85 300S-303S.

36. Macdonald HM, New SA, Fraser WD, et al. (2005) Low dietary potassium intakes and high dietary estimates of net endogenous acid production are associated with low bone mineral density in premenopausal women and increased markers of bone resorption in postmenopausal women. Am J Clin Nutr 81, 923-933.

37. Welch AA, Bingham SA, Reeve J, et al. (2007) More acidic dietary acid-base load is associated with reduced calcaneal broadband ultrasound attenuation in women but not in men: results from the EPIC-Norfolk cohort study. Am J Clin Nutr 85, 1134-1141.

38. Frost HM (1987) Bone "mass" and the "mechanostat": a proposal. Anat Rec 219, 1-9.

39. Leonard MB (2007) A structural approach to the assessment of fracture risk in children and adolescents with chronic kidney disease. Pediatr Nephrol 22, 1815-1824.

40. Fewtrell MS (2003) Bone densitometry in children assessed by dual $\mathrm{X}$ ray absorptiometry: uses and pitfalls. Arch Dis Child 88, 795-798.

41. Loud KJ \& Gordon CM (2006) Adolescent bone health. Arch Pediatr Adolesc Med 160, 1026-1032.

42. Biro G, Hulshof KF, Ovesen L, et al. (2002) Selection of methodology to assess food intake. Eur J Clin Nutr 56, Suppl. 2, S25-S32. 